\title{
Pengaruh Keadilan Distributif Kompensasi dan Keadilan Prosedural Kompensasi terhadap Employee Engagement dan Kinerja Karyawan PT. Ameya Livingstyle Indonesia
}

\author{
Aginza Dio Rama Pandita ${ }^{1}$, Musoli ${ }^{2}$ \\ ${ }^{1}$ Universitas Muhammadiyah Yogyakarta \\ Email : aginzadioramapandita@yahoo.com \\ ${ }^{2}$ Universitas 'Aisyiyah Yogyakarta \\ Email : musoli27@gmail.com
}

\begin{abstract}
The purpose of this research are to know and analyze the influence of distributive justice compensation to employee engagement of PT. Ameya Livingstyle Indonesia, knowing and analyzing the effect of procedural fairness of compensation on employee engagement of PT. Ameya Livingstyle Indonesia, knowing and analyzing the influence of distributive justice compensation on the performance of employees of PT. Ameya Livingstyle Indonesia, knowing and analyzing the effect of procedural fairness of compensation on employee performance of PT. Ameya Livingstyle Indonesia, and know and analyze the influence of employee engagement on the performance of employees of PT. Ameya Livingstyle Indonesia. This research are 93 permanent employees of PT. Ameya Livingstyle Indonesia. Sampling technique using Purposive sampling is sampling method where the sample is taken based on certain criteria, which is only permanent employee of PT. Ameya Livingstyle Indonesia numbering 93 people. Data analysis method using Linear Regression Model Structural Equation Model (SEM) AMOS in this research is used to know and analyze impact. The results of the analysis is identified most respondents assess Distributive Justice Compensation Employees known PT. Ameya Livingstyle Indonesia, High (Mean 4.17). Identified most of the respondents judge Procedural Justice Compensation Employees remain PT. Ameya Livingstyle Indonesia, High (Mean 3.98). Known most respondents rate Employee Engagement Employees Employees permanent PT. Ameya Livingstyle Indonesia, Height (Mean 4.02). Known most respondents rate Employee Performance PT. Ameya Livingstyle Indonesia, Height (Mean 4.08). The results of the analysis show that Distributive Justice Equity significantly affects Employee Engagement Employees PT. Ameya Livingstyle Indonesia (value of probability t-count (0.000) <Level of Significant (0,05)), Procedural Justice Compensation has significant effect to Employee Engagement Employee PT. Ameya Livingstyle Indonesia (value of probability t-count (0.000) $<$ Level of Significant (0,05)), Distributive Justice Compensation has significant effect to Employee Performance of PT. Ameya Livingstyle Indonesia (value probability t-count (0.040) <Level of Significant $(0,05))$, Justice Prosedural Compensation has a significant effect on Employee Performance Employees PT. Ameya Livingstyle Indonesia (probability value t-count $(0,000)<$ Level of Significant $(0,05))$. This can be interpreted, if the Justice Procedural Compensation increases, then Employee Performance Employees PT. Ameya Livingstyle Indonesia has increased, Employee Engagement has a simultaneous influence on Employee Performance Employees PT. Ameya Livingstyle Indonesia (probability value t-count $(0,000)$ $<$ Level of Significant $(0,05))$.
\end{abstract}

Keywords: Distributive Justice Compensation, Procedural Justice Compensation, Employee Engagement, Employee Performance.

(C) 2019 JBTI. All rights reserved

Article history : Received 27 Jul 2018; Revised 20 Agt 2018; Accepted 20 Sep 2018

\section{PENDAHULUAN}

PT. Ameya Livingstyle Indonesia adalah salah satu pabrik besar yang mengurusi ribuan karyawan. Fenomena ketidakadilan ini dalam organisasi dapat digambarkan sebagai pola-pola, skema, bagian yang menunjukkan garis-garis perintah, kedudukan karyawan, hubungan- 
hubungan yang ada dan lain sebagainya (Hasibuan, 2003). Dalam organisasi terdapat lebih dari satu sumber daya yang dimiliki. Di antara sumberdaya yang dimiliki oleh perusahaan, Sumber Daya Manusia (SDM) merupakan sumber daya yang sangat penting diantara sumber daya lainnya. Tanpa SDM, sumber daya lain yang dimiliki perusahaan tidak dapat dikelola menjadi suatu produk. Pada dasarnya setiap perusahaan memiliki visi dan misi tertentu yang harus dicapai, salah satunya adalah untuk memperoleh profit.

Kinerja adalah melakukan suatu kegiatan keadilan menjadi suatu hal yang semakin penting pada masa sekarang ini. Persoalan ketidakadilan menyebabkan ketidakpuasan yang apabila tidak segera diselesaikan dapat menimbulkan perilaku menyimpang di tempat kerja. Berbagai perilaku menyimpang seperti datang terlambat, mengabaikan perintah atasan, atau menggunakan barang perusahaan di luar kewenangannya merupakan bentuk penyimpangan yang dilakukan secara sadar untuk mengganggu perusahaan (Aquino et al., dalam Kadaruddin, dkk., 2007).

Keadilan merupakan nilai universal dan menjadi hak asasi yang telah diterima secara luas (Held dalam Mahmudah, 2010). Keadilan dapat diartikan sebagai bentuk yang dinilai atau dipersepsikan baik oleh anggota dalam organisasi. Sheppard et al., (Beugre, 2002) mengajukan definisi keadilan yang lebih tepat bagi wacana organisasi yang mendasarkan pada dua prinsip, Pada akhirnya ketidakadilan hanya akan menghilangkan ikatan di antara anggota organisasi, sangat menyakitkan bagi individu, dan berbahaya bagi perusahaan (Cropanzano et al., 2007).

Distribusi berdasarkan kebutuhan memiliki konsep bahwa bagian penerimaan karyawan dipengaruhi oleh kebutuhannya berkaitan dengan pekerjaan. Semakin banyak kebutuhan untuk para karyawan, maka penerimaan dari bekerja menjadi semakin tinggi (Deutsch dalam Beugre, 2002). Dari kajian teoritikal di atas dapat disimpulkan bahwa keadilan distributif adalah merupakan sebuah persepsi tentang nilai-nilai yang diterima oleh karyawan berdasarkan hasil/penerimaan suatu keadaan atau barang yang mampu mempengaruhi kesejahteraan karyawan.

Mengacu pendapat Cropanzano et al., (2007) bahwa sebuah organisasi yang adil salah satunya adalah dicirikan dengan prosedur yang menjamin hal itu sebagai pernyataan, proses, peringatan, dan sebagainya. Keadilan prosedural melibatkan karakteristik formal sebuah sistem, dan salah satu indikator yang jelas dari keadilan prosedural adalah adanya beberapa mekanisme yang mengatur secara jelas bagi karyawan untuk mengatakan tentang sesuatu yang terjadi dalam pekerjaannya. Magner dkk., (Beugre, 2002) berpendapat bahwa manajer atau pimpinan seharusnya menghindari penggunaan prosedur yang berubah-ubah dan sewenang-wenang dalam mengalokasikan sumber daya kerja yang ada.

Keadilan prosedural kompensasi fokus pada proses keputusan yang diambil untuk menentukan luaran pekerjaan yang dipandang masuk akal. Para karyawan ingin mengetahui keputusan apa yang diambil dan bagaimana proses keputusan dibuat. Studi keadilan merupakan bagian penting kajian motivasi di tempat kerja yang berawal dari keadilan distributif sampai dengan keadilan prosedural sebagai sentral kajian keadilan di tempat kerja. Kemudian terkait dengan employee engagement yang merupakan rasa keterikatan secara emosional dengan pekerjaan dan organisasi, termotivasi dan mampu memberikan kemampuan terbaik mereka untuk membantu sukses dari serangkaian manfaat nyata bagi organisasi dan individu (McLeod, 2009). David Guest, percaya hal ini sangat membantu untuk melihat employee engagement sebagai cara kerja yang dirancang untuk memastikan bahwa karyawan berkomitmen untuk tujuan dan nilainilai organisasi mereka, termotivasi untuk memberikan kontribusi bagi keberhasilan organisasi, dan pada saat yang sama agar mampu meningkatkan rasa kesejahteraan diri.

Penelitian ini merupakan mereplikasi dan memodifikasi dari penelitian Atmojo \& Heru (2016) dengan judul "Pengaruh Keadilan Distributif dan Prosedural Kompensasi terhadap Kepuasan Kerja dan Kinerja Paramedis di Rumah Sakit" dan penelitian Margaretha \& Elisabeth (2012) dengan judul "Keadilan Prosedural dan Keadilan Distributif sebagai Prediktor Employee Engagement". Mendasarkan penelitian sebelumnya dan uraian-uraian yang dikemukakan di atas, peneliti berkeinginan untuk melakukan penelitian dengan judul "Pengaruh Keadilan Distributif 
Kompensasi dan Keadilan Prosedural Kompensasi terhadap Employee Engagement dan Kinerja Karyawan PT. Ameya Livingstyle Indonesia”.

\section{KAJIAN TEORI}

Kinerja pegawai merupakan tingkat kemampuan dan tingkat keberhasilan seseorang di dalam melaksanakan tugas dan tanggung jawabnya. Mangkuprawira (2007) mengemukakan bahwa kinerja adalah hasil kerja secara kualitas dan kuantitas yang dicapai oleh seorang pegawai dalam melaksanakan tugasnya sesuai dengan tanggung jawab yang diberikan kepadanya. Handoko (2008), menyebutkan ada dua teori utama untuk mengukur kinerja seseorang adalah efisiensi dan efektivitas. Efisiensi adalah kemampuan untuk menyelesaikan pekerjaan dengan tepat dan benar, sedangkan efektivitas merupakan kemampuan untuk memilih tujuan yang tepat untuk pencapaian tujuan yang telah ditetapkan. Dengan kata lain, seorang karyawan yang efektif dapat memilih pekerjaan yang harus dilakukan atau cara yang tepat untuk pencapaian tujuan.

Tujuan-tujuan khusus itu dapat digolongkan menjadi dua bagian besar, yaitu evaluasi dan pengembangan. Kedua tujuan tersebut tidaklah saling terpisahkan, tetapi memang secara tidak langsung berbeda dari segi orientasi waktu, metode-metode dan peran atasan dan bawahan. Keadilan distributif adalah penilaian karyawan mengenai keadilan atas hasil (outcome) yang diterima karyawan dari organisasi (Greenberg dalam Kadaruddin, dkk., 2007). Keadilan distributif adalah keadilan yang paling sering dinilai dengan dasar keadilan hasil, yang menyatakan bahwa karyawan seharusnya menerima upah/gaji yang sesuai dengan pemasukan dan pengeluaran mereka secara relatif dengan perbandingan referen/lainnya (Adams dalam Irawan, 2015).

Menurut Yamagishi (Budiarto \& Wardani, 2005), keadilan distributif dalam psikologi meliputi segala bentuk distribusi di antara anggota kelompok dan pertukaran antar dua orang. Keadilan distributif yang dimaksudkan tidak hanya berasosiasi dengan pemberian, tetapi juga meliputi pembagian, penyaluran, penempatan, dan pertukaran. Keadilan distributif secara konseptual juga berkaitan dengan distribusi keadaan dan barang yang akan berpengaruh terhadap kesejahteraan individu. Kesejahteraan individu yang dimaksudkan meliputi aspek-aspek fisik, psikologis, ekonomi, dan sosial. Tujuan distribusi di sini adalah kesejahteraan (Budiarto \& Wardani, 2005). Cara lain untuk menyatakan hal ini adalah bahwa organisasi mendistribusikan penghargaan kepada para karyawannya tersebut berdasarkan beberapa skema atau persamaan. Para karyawan membentuk opini yang berkaitan dengan skema pendistribusian apakah penghargaan itu adil atau tidak. Perhatian mengenai keadilan distributif dirasakan adil dari penempatan hasil-hasil atau pemberian penghargaan kepada para anggota organisasi (Budiarto \& Wardani, 2005).

Keadilan prosedural menjelaskan bahwa orang tidak hanya melakukan evaluasi hasil, namun juga melakukan evaluasi prosedur untuk menentukan alokasi tersebut. (Tyler \& Blader, 2003). Tjahjono (2008) menegaskan bahwa keadilan prosedural merupakan mekanisme yang adil untuk memperoleh kesejahteraan yang diharapkan. Hal tersebut dijelaskan Thibaut dan Walker (1988) berbasis pada kepentingan pribadi dan Lind dan Tyler (Atmojo, \& Heru, 2016) berbasis pada nilai-nilai kelompok. Keadilan prosedural berhubungan pada keadilan prosedural yang digunakan untuk menentukan hasil-hasil yang terdistribusi yaitu seperti beban kerja, penghasilan dan yang lain (Leventhal, 1980). Karena studi ini berdasarkan pada sistem keadilan hukum untuk meredakan suatu permaslahan atau pertikaian hukum, mereka menganggap dan mempertimbangkan lingkungan individu menjadi nilai penting. Menurut mereka, untuk mengatasi suatu pertikaian atau permasalahan akan kepentingan pribadi dan distribusi hasil akhir, maka prosedur bernilai tinggi dalam pengendalian proses atas sebuah konflik sebaiknya digunakan.

Niehoff dan Moorman (1993) menjelaskan indikator keadilan prosedural yang meliputi fair formal prosedure yang merujuk pada ada atau tidak adanya kesesuaian prosedur yang diyakini menjadi pokok pendistribusian penghargaan yang mempengaruhi persepsi keadilan dan 
interactional justice yang merujuk pada keadilan dari perlakuan atau treatment yang diterima karyawan dalam kaitannya secara prosedur. Employee engagement merupakan rasa keterikatan secara emosional dengan pekerjaan dan organisasi, termotivasi dan mampu memberikan kemampuan terbaik mereka untuk membantu sukses dari serangkaian manfaat nyata bagi organisasi dan individu (McLeod, 2009). David Guest, percaya hal ini sangat membantu untuk melihat employee engagement sebagai cara kerja yang dirancang untuk memastikan bahwa karyawan berkomitmen untuk tujuan dan nilai-nilai organisasi mereka, termotivasi untuk memberikan kontribusi bagi keberhasilan organisasi, dan pada saat yang sama agar mampu meningkatkan rasa kesejahteraan diri.

Membangun budaya yang engagement merupakan dasar. Kata-kata dan tindakan kolektif dari semua pemimpin membentuk budaya organisasi. Budaya yang engagement bukan hanya hangat dan ramah. Inspirasi komitmen dan kepercayaan pada employee engagement tidak hanya memahami apa yang perlu dilakukan, tetapi juga cukup peduli untuk menerapkan upaya bijaksana, (White, 2011). Dari berbagai faktor yang mempengaruhi employee engagement di atas, sebagian besar menempatkan pada lingkungan kerja yang mendukung kinerja tinggi di organisasi sebagai pembentuk engagement pada karyawan.

Hasil penelitian Atmojo dan Heru (2016) dengan judul "Pengaruh Keadilan Distributif dan Prosedural Kompensasi terhadap Kepuasan Kerja dan Kinerja Paramedis di Rumah Sakit". Penelitian ini membahas keadilan organisasi termasuk kompensasi keadilan distributif dan kompensasi keadilan prosedural terhadap kinerja karyawan baik secara langsung maupun tidak langsung dipengaruhi oleh kepuasan kerja.

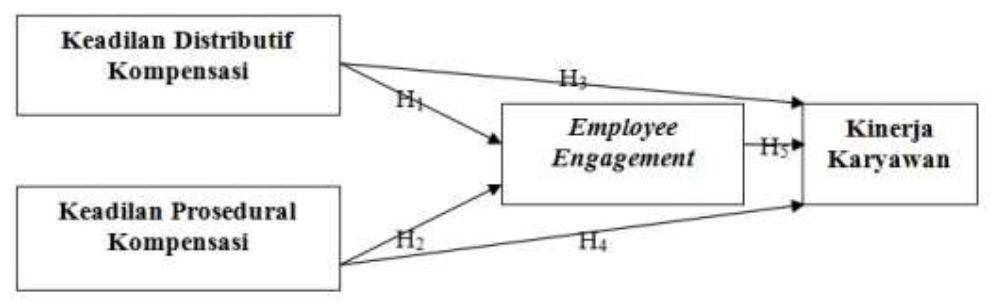

Gambar 2.1

Kerangka Pemikiran

Sumber: Dimodifikasi dari Atmojo dan Heru (2016); Margaretha dan Elisabeth (2012)

Dimensi keamanan yang diperkenalkan oleh Kahn (Saks, 2006) melibatkan situasi sosial yang dapat diprediksi dan konsisten. Bagi banyak organisasi, hal ini merupakan sesuatu yang penting untuk dapat diprediksi dan konsisten dalam mendistribusikan penghargaan seperti halnya prosedur yang digunakan untuk mengalokasikan hal tersebut. Sementara keadilan distributif menyinggung salah satu persepsi keadilan dari hasil-hasil keputusan, keadilan prosedural menunjuk pada keadilan yang diterima dari cara dan proses-proses yang digunakan untuk menentukan jumlah dan distibusi sumber daya (Colquitt, 2001; Rhoades et al., 2001; dalam Saks, 2006).

Pengaruh dari persepsi keadilan pada berbagai macam hasil kerja mungkin hasil dari sebagian employee engagement. Dengan kata lain, ketika para karyawan memiliki persepsi yang tinggi tentang keadilan dalam organisasi mereka, dipastikan mereka merasa diwajibkan atau diharuskan untuk berlaku adil di dalam memainkan peran mereka dengan memberi lebih besar melebih tingkat engagement. Di sisi lain, persepsi keadilan yang rendah kemungkinan di sebabkan para karyawan menarik diri dan melepaskan diri mereka sendiri dari peran kerja mereka. Keadilan juga merupakan salah satu kondisi kerja dalam model engagement.

Keadilan distributif kompensasi sebagai perlakuan adil bagi karyawan ditinjau dari gaji atau upah, jam kerja, promosi, dan reward lainnya. Jika para manajer tidak merancang upah dan kebijakan promosi sesuai pendidikan, kepakaran, dan kecakapan, serta kinerja para karyawan, mereka akan kecewa dan tidak berkomitmen pada organisasi (Murtaza et al., 2011). Hasil 
penelitian Atmojo \& Heru (2016) yang menyatakan bahwa Keadilan Distributif Kompensasi berpengaruh signifikan terhadap Kinerja Karyawan Paramedis di Rumah Sakit.

Keadilan prosedural adalah keadilan yang memperhatikan mekanisme yang mendukung pemberdayaan karyawan dan memberi dukungan kepada karyawan. Keadilan prosedural adalah mengacu pada keadilan peraturan dan prosedur dimana penghargaan didistribusikan (Alexander \& Ruderman dalam Supardi, 2008). Mengacu pendapat Cropanzano et al., (2007) bahwa sebuah organisasi yang adil salah satunya adalah dicirikan dengan prosedur yang menjamin hal itu sebagai pernyataan, proses, peringatan, dan sebagainya.

Employee engagement merupakan rasa keterikatan secara emosional dengan pekerjaan dan organisasi, termotivasi dan mampu memberikan kemampuan terbaik mereka untuk membantu sukses dari serangkaian manfaat nyata bagi organisasi dan individu (McLeod, 2009). David Guest, percaya hal ini sangat membantu untuk melihat employee engagement sebagai cara kerja yang dirancang untuk memastikan bahwa karyawan berkomitmen untuk tujuan dan nilainilai organisasi mereka, termotivasi untuk memberikan kontribusi bagi keberhasilan organisasi, dan pada saat yang sama agar mampu meningkatkan rasa kesejahteraan diri.

\section{Hipotesis :}

$\mathrm{H}_{1} \quad$ :Keadilan distributif kompensasi berpengaruh signifikan terhadap employee engagement karyawan PT. Ameya Livingstyle Indonesia.

$\mathrm{H}_{2}$ :Keadilan prosedural kompensasi berpengaruh signifikan terhadap employee engagement karyawan PT. Ameya Livingstyle Indonesia.

$\mathrm{H}_{3} \quad$ :Keadilan distributif kompensasi berpengaruh signifikan terhadap kinerja karyawan PT. Ameya Livingstyle Indonesia.

$\mathrm{H}_{4}$ :Keadilan prosedural kompensasi berpengaruh signifikan terhadap kinerja karyawan PT. Ameya Livingstyle Indonesia.

$\mathrm{H}_{5} \quad$ :Employee engagement berpengaruh signifikan terhadap kinerja karyawan PT. Ameya Livingstyle Indonesia.

\section{METODE PENELITIAN}

Jenis penelitian ini adalah penelitian kuantitatif dengan menggunakan metode survei (Arikunto, 2013). Metode survei yakni pengamatan dan penyelidikan secara kritis untuk mendapatkan keterangan yang tepat terhadap suatu persoalan dan obyek tertentu di daerah kelompok komunitas atau lokasi tertentu akan ditela'ah (Ruslan, 2004).

Populasi dalam penelitian ini adalah seluruh karyawan tetap PT. Ameya Livingstyle Indonesia yang berjumlah 93 orang. Dalam penelitian ini sampel yang diambil adalah seluruh karyawan PT. Ameya Livingstyle Indonesia. Jumlah sampel dalam penelitian ini yaitu 93 orang karyawan tetap PT. Ameya Livingstyle Indonesia. Metode pengambilan sampel dalam penelitian ini adalah teknik purposive sampling. Purposive sampling adalah metode pengambilan sampel dimana sampel diambil berdasarkan kriteria-kriteria tertentu, yaitu hanya karyawan tetap PT. Ameya Livingstyle Indonesia yang berjumlah 93 orang (Rahayu, 2005).

Data yang digunakan dalam penelitian ini adalah data primer, Teknik pengumpulan data dengan metode kuesioner. Kuesioner dalam metode pengumpulan data penelitian dan pada kondisi tertentu pihak peneliti tidak perlu hadir (Ruslan, 2004). Data yang dibutuhkan berupa jawaban responden (penilaian) atas pertanyaan atau pernyataan dalam kuesioner yang disebarkan. Kuesioner diadaptasi dari penelitian Atmojo dan Heru (2016).

\section{Definisi Operasional dan Pengukuran Variabel}

\section{a. Keadilan Distributif Kompensasi (X1)}

Keadilan distributif kompensasi adalah sebagai perlakuan adil bagi karyawan ditinjau dari gaji atau upah, jam kerja, promosi, dan reward lainnya. Indikator diukur dari keadilan distributif kompensasi meliputi (Niehoff \& Moorman, 1993): 
1) Kesesuaian jadwal kerja dengan kompensasi

2) Tingkat gaji

3) Kesesuaian beban kerja dengan kompensasi

4) Penghargaan atau promosi yang didapatkan

5) Kesesuaian tanggung jawab pekerjaan dengan kompensasi

b. Keadilan Prosedural Kompensasi (X2)

Keadilan prosedural kompensasi adalah fokus pada proses keputusan yang diambil untuk menentukan luaran pekerjaan yang dipandang masuk akal. Variabel keadilan prosedural kompensasi terdiri dari beberapa indikator sebagai berikut (Niehoff \& Moorman, 1993) :

1) Fair formal procedure (prosedur formal yang adil)

2) Interactional justice (keadilan interaksional).

c. Employee Engagement (Z)

Employee engagement adalah sikap yang positif yang dimiliki karyawan dengan penuh makna, dan energi motivasi yang tinggi, resiliensi dan keinginan untuk berusaha, dan tidak menyerah dalam menghadapi tantangan dengan konsentrasi penuh terhadap suatu tugas yang disesuaikan dengan nilai dan tujuan organisasi. Variabel employee engagement diukur dari beberapa indikator sebagai berikut (Schaufeli et al., 2003):

1) Aspek Vigor

2) Aspek Dedication

3) Aspek Absorption

\section{d. Kinerja Karyawan (Y)}

Kinerja karyawan adalah sebagai fungsi interaksi antara kemampuan dan motivasi (Robbins, 2008). Menurut Prawirosentono (2008), kinerja dijabarkan dengan beberapa item sebagai berikut:

1) Dapat menyelesaikan sejumlah pekerjaan

2) Dapat menyelesaikan pekerjaan dengan teliti

3) Memiliki pengetahuan

4) Memiliki kemampuan bekerjasama

5) Memiliki tanggung jawab

6) Memiliki sikap kerja

7) Memiliki inisiatif.

Pengukuran variabel (instrumen penelitian) dalam penelitian ini, yaitu mengukur variabel keadilan distributif kompensasi, keadilan prosedural kompensasi, employee engagement, dan kinerja karyawan. Menurut Sugiyono (2010), skala Likert digunakan untuk mengukur sikap, pendapat, dan persepsi seseorang atau sekelompok orang tentang fenomena sosial. Dalam penelitian fenomena sosial ini telah ditetapkan secara spesifik oleh peneliti yang selanjutnya disebut variabel penelitian.

\section{Uji Validitas}

Perhitungan validitas alat ukur penelitian ini dilakukan dengan bantuan program komputer AMOS 21 . Jika nilai r-hitung $\left(\mathrm{r}_{\mathrm{xy}}\right)>\mathrm{r}$-tabel, sehingga seluruh pertanyaan dalam kuesioner pada item-item pertanyaan pada variabel penelitian adalah valid.

\section{Uji Reliabilitas}


Untuk mengetahui sejauh mana alat pengukur benar-benar mengukur apa yangs seharusnya diukur (Santoso, 2010). Untuk pengujian reliabilitas dilakukan dengan teknik Cronbach Alpha. Suatu instrumen penelitian dinyatakan reliabel apabila nilai $\mathrm{r}_{\text {alpha }}>0,60$. Perhitungan reliabilitas alat ukur penelitian ini dilakukan dengan bantuan program komputer AMOS 21. .

\section{Analisis Regresi Linier Model SEM (Structural Equation Model)}

Analisis Regresi Linier Model SEM (Structural Equation Model) dalam penelitian ini digunakan untuk mengetahui dan menganalisis pengaruh keadilan distributif kompensasi terhadap kinerja karyawan PT. Ameya Livingstyle Indonesia, Model persamaan Regresi Linier SEM (Structural Equation Model) yang digunakan dengan formula sebagai berikut:

$$
\begin{aligned}
& Z=b 0+b 1 X 1+b 2 X 2+e i \\
& Y=b 0+b 1 X 1+b 2 X 2+b 3 Z+e i
\end{aligned}
$$

Di mana :

$\mathrm{Y} \quad=$ Kinerja Karyawan

$\mathrm{X}=$ Keadilan Distributif Kompensasi.

$\mathrm{X} 2$ = Keadilan Prosedural Kompensasi

$\mathrm{Z} \quad=$ Employee Engagement

$\mathrm{b} 0=$ Konstanta

b1-b3 = Koefisien Regresi

ei $=$ Error Term

\section{Uji Kualitas Data}

Tindakan pertama yang dilakukan adalah mengevaluasi apakah data yang digunakan dapat memenuhi asumsi-asumsi SEM. Asumsi-asumsi SEM yang harus dipenuhi dalam prosedur pengumpulan dan pengolahan data yang dianalisis dengan pemodelan SEM adalah Normalitas dan Outlier.

\section{Uji Structural Model}

Evaluasi atas kriteria Goodness of Fit merupakan evaluasi atas uji kelayakan suatu model dengan beberapa kriteria kesesuaian indeks dan cut off valuenya, guna menyatakan apakah sebuah model dapat diterima atau ditolak.

a. Uji Chi-square, dimana model dipandang baik atau memuaskan bila nilai Chi-square nya rendah. Semakin kecil nilai chi-square semakin baik model itu dan nilai signifikansi lebih besar dari cut off value ( $\mathrm{p}>0,05)$.

b. CMIN/DF adalah The Minimum Sample Discrepancy Function yang dibagi dengan Degree of Freedom. Chi-square dibagi DF-nya disebut chi-square relatif. Bila nilai chi-square relatif kurang dari 2,0 atau 3,0 adalah indikasi dari acceptable fit antara model dan data.

c. GFI (Goodness of Fit Index) adalah ukuran non statistikal yang mempunyai rentang nilai antara 0 (poor fit) sampai dengan 1,0 (perfect fit). Nilai yang tinggi dalam indeks ini menunjukkan sebuah better fit.

d. AGFI (Adjusted Goodness of Fit Index), dimana tingkat penerimaan yang direkomendasikan adalah bila AGFI mempunyai nilai sama dengan atau lebih besar dari 0,90.

e. TLI (Tucker Lewis Index), merupakan incremental index yang membandingkan sebuah model yang diuji terhadap sebuah baseline model, dimana sebuah model $\geq 0,95$ dan nilai yang mendekati 1 menunjukkan a very good fit.

f. CFI (Comparative Fit Index), dimana bila mendekati 1, mengindikasi tingkat fit yang paling tinggi. Nilai yang direkomendasikan adalah $\mathrm{CFI} \geq 0,95$. 
g. RMSEA (The Root Mean Square Error of Approximation), yang menunjukkan goodness of fit yang dapat diharapkan bila model diestimasi dalam populasi. Nilai RMSEA yang lebih kecil atau sama dengan 0,08 merupakan indeks untuk dapat diterimanya model yang menunjukkan sebuah close fit dari model itu berdasarkan degrees of freedom.

Tabel 3.1

Goodness of Fit Indices

\begin{tabular}{|l|c|}
\hline Goodness of Fit Index & Cut off Value \\
\hline Chi-square & Diharapkan kecil \\
Significant Probability & $\geq 0,05$ \\
CMIN/DF & $\leq 0,20$ \\
RMSEA & $\leq 0,80$ \\
GFI & $\geq 0,90$ \\
AGFI & $\geq 0,90$ \\
TLI & $\geq 0,95$ \\
CFI & $\geq 0,95$ \\
\hline
\end{tabular}

Sumber: Ghozali (2008).

Penelitian ini menggunakan metode survey, menurut Sugiyono (2013) penelitian survey adalah penelitian yang dilakukan dengan menggunakan populasi besar maupun kecil, tetapi data yang dipelajari adalah data dari sampel yang diambil dari populasi tersebut, untuk menemukan kejadian-kejadian ralatif, distribusi dan hubungan-hubungan antar variabel sosiologis maupun psikologis. Metode pengumpulan data dalam penelitian ini menggunakan teknik wawancara dan kuisioner. populasi dari penelitian ini adalah semua pengusaha yang bergerak di sektor perdagangan dan sektor jasa, sampel dalam penelitian ini menggunakan 100 sampel yang terdiri dari 90 sampel dari sektor perusahaan perdagangan, 5 sampel dari sektor jasa peruahaan perhotelan dan 5 sampel dari sektor jasa perusahaan transportasi. Teknik pengambilan sampel dalam penelitian ini menggunakan non probability sampling. Hal ini disebabkan tidak diketahuinya probabilitas sampel yang akan dipilih. Dikarenakan populasi dalam penelitian ini jumlahnya tidak terbatas (infinit), maka Jumlah sample penelitian ditetapkan dengan menggunakan sampling kuota. Menurut Sugiyono (2013) samplin kuota adalah teknik untuk mengumpulkan sampel dari populasi yang mempunyai ciri-ciri tertentu sampai jumlah (kuota) yang dinginkan.

\section{HASIL DAN PEMBAHASAN}

Tabel 4.1

Hasil Uji Validitas Item-item Variabel Keadilan Distributif Kompensasi $\left(\mathrm{X}_{1}\right)$ dan Keadilan Prosedural Kompensasi $\left(\mathrm{X}_{2}\right)$

\begin{tabular}{|c|c|c|c|}
\hline Indikator & Rxy & r-tabel & Keterangan \\
\hline X1.1 & 0,733 & 0,202 & Valid \\
\hline X1.2 & 0,673 & 0,202 & Valid \\
\hline X1.3 & 0,726 & 0,202 & Valid \\
\hline X1.4 & 0,714 & 0,202 & Valid \\
\hline X1.5 & 0,726 & 0,202 & Valid \\
\hline X1.6 & 0,639 & 0,202 & Valid \\
\hline X1.7 & 0,684 & 0,202 & Valid \\
\hline X1.8 & 0,695 & 0,202 & Valid \\
\hline X2.1 & 0,779 & 0,202 & Valid \\
\hline X2.2 & 0,642 & 0,202 & Valid \\
\hline X2.3 & 0,728 & 0,202 & Valid \\
\hline X2.4 & 0,732 & 0,202 & Valid \\
\hline X2.5 & 0,746 & 0,202 & Valid \\
\hline
\end{tabular}




\begin{tabular}{|c|c|c|c|}
\hline Indikator & Rxy & r-tabel & Keterangan \\
\hline $\mathrm{X} 2.6$ & 0,658 & 0,202 & Valid \\
\hline $\mathrm{X} 2.7$ & 0,735 & 0,202 & Valid \\
\hline
\end{tabular}

Sumber : Data Primer Diolah, 2017

Dari Tabel 4.1 tersebut di atas dapat diketahui bahwa nilai rxy $>0,202$, sehingga seluruh pertanyaan dalam kuesioner pada item-item pertanyaan pada variabel Keadilan Distributif Kompensasi dan Keadilan Prosedural Kompensasi adalah valid.

Tabel 4.2

Hasil Uji Validitas Item-item

Variabel Employee Engagement (Z) dan Kinerja Karyawan (Y)

\begin{tabular}{|c|c|c|c|}
\hline Indikator & Rxy & r-tabel & Keterangan \\
\hline Z1.1 & 0,762 & 0,202 & Valid \\
\hline Z1.2 & 0,729 & 0,202 & Valid \\
\hline Z1.3 & 0,661 & 0,202 & Valid \\
\hline Z1.4 & 0,707 & 0,202 & Valid \\
\hline Z1.5 & 0,659 & 0,202 & Valid \\
\hline Z1.6 & 0,719 & 0,202 & Valid \\
\hline Z1.7 & 0,775 & 0,202 & Valid \\
\hline Z1.8 & 0,733 & 0,202 & Valid \\
\hline Z1.9 & 0,588 & 0,202 & Valid \\
\hline Z1.10 & 0,673 & 0,202 & Valid \\
\hline Z1.11 & 0,686 & 0,202 & Valid \\
\hline Z1.12 & 0,686 & 0,202 & Valid \\
\hline Z1.13 & 0,719 & 0,202 & Valid \\
\hline Z1.14 & 0,696 & 0,202 & Valid \\
\hline Y1.1 & 0,744 & 0,202 & Valid \\
\hline Y1.2 & 0,748 & 0,202 & Valid \\
\hline Y1.3 & 0,791 & 0,202 & Valid \\
\hline Y1.4 & 0,609 & 0,202 & Valid \\
\hline Y1.5 & 0,628 & 0,202 & Valid \\
\hline Y1.6 & 0,706 & 0,202 & Valid \\
\hline Y1.7 & 0,736 & 0,202 & Valid \\
\hline Y1.8 & 0,636 & 0,202 & Valid \\
\hline Y1.9 & 0,768 & 0,202 & Valid \\
\hline Y1.10 & 0,770 & 0,202 & Valid \\
\hline Y1.11 & 0,679 & 0,202 & Valid \\
\hline Y1.12 & 0,664 & 0,202 & Valid \\
\hline Y1.13 & 0,655 & 0,202 & Valid \\
\hline Y1.14 & 0,754 & 0,202 & Valid \\
\hline Sumber & Da & \\
\hline
\end{tabular}

Sumber : Data Primer Diolah, 2017.

Dari Tabel 4.2 tersebut di atas dapat diketahui bahwa nilai rxy > 0,202, sehingga seluruh pertanyaan dalam kuesioner pada item-item pertanyaan pada variabel Employee Engagement dan Kinerja Karyawan adalah valid.

Tabel 4.3

Hasil Uji Reliabilitas

\begin{tabular}{|c|c|c|c|}
\hline Variabel & Cronbach Alpha & Nilai Kritis & Keterangan \\
\hline Keadilan Distributif Kompensasi & 0,905 & $\geq 0,60$ & Reliabel \\
\hline Keadilan Prosedural Kompensasi & 0,902 & $\geq 0,60$ & Reliabel \\
\hline
\end{tabular}




\begin{tabular}{|l|c|c|c|}
\hline \multicolumn{1}{|c|}{ Variabel } & Cronbach Alpha & Nilai Kritis & Keterangan \\
\hline Employee Engagement & 0,937 & $\geq 0,60$ & Reliabel \\
\hline Kinerja Karyawan & 0,940 & $\geq 0,60$ & Reliabel \\
\hline
\end{tabular}

Sumber: Data Primer Diolah, 2017.

Dari Tabel 4.3 tersebut di atas dapat diketahui bahwa koefisien Cronbach's Alpha > 0,60 sehingga seluruh pertanyaan dalam kuesioner pada item-item pertanyaan pada variabel Keadilan Distributif Kompensasi, Keadilan Prosedural Kompensasi, Employee Engagement, dan Kinerja Karyawan adalah reliabel.

\section{Analisis Deskripsi Variabel Penelitian}

Keadilan Distributif Kompensasi, Keadilan Prosedural Kompensasi, Employee Engagement, dan Kinerja Karyawan. Analisis data ini melalui 2 (dua) tahap, yaitu analisis deskriptif dan analisis kuantitatif. Nilai rata-rata dari masing-masing responden dari kelas interval dengan jumlah kelas sama dengan 5, sehingga dapat dihitung sebagai berikut:

$$
\begin{aligned}
& \text { Interval }=\frac{\text { Nilai Maksimum Nilai Minimum }}{\text { Jumlah Kelas }} \\
& \text { Interval }=\frac{\text { Nilai Max }- \text { Nilai Min }}{\text { Jumlah Kelas }} \\
& \text { Interval }=\frac{5-1}{5}=0,80
\end{aligned}
$$

Adapun kategori dari masing-masing interval adalah sebagai berikut :

Tabel 4.4

Interval Skala

\begin{tabular}{|l|l|}
\hline \multicolumn{1}{|c|}{ Interval } & \multicolumn{1}{c|}{ Kategori } \\
\hline $1,00 \mathrm{~s} / \mathrm{d} 1,79$ & Sangat Rendah \\
\hline $1,80 \mathrm{~s} / \mathrm{d} 2,59$ & Rendah \\
\hline $2,60 \mathrm{~s} / \mathrm{d} 3,39$ & Cukup Tinggi \\
\hline $3,40 \mathrm{~s} / \mathrm{d} 4,19$ & Tinggi \\
\hline $4,20 \mathrm{~s} / \mathrm{d} 5,00$ & Sangat Tinggi \\
\hline
\end{tabular}

\section{Variabel Keadilan Distributif Kompensas}

Tabel 4.5

Penilaian Responden terhadap Keadilan Distributif Kompensasi

\begin{tabular}{|c|l|l|l|}
\hline No. & \multicolumn{1}{|c|}{ Item Variabel } & Mean & \multicolumn{1}{|c|}{ Kategori } \\
\hline 1 & $\begin{array}{l}\text { Jadwal kerja saya telah sesuai dengan kompensasi } \\
\text { yang saya terima }\end{array}$ & 4,46 & Sangat Tinggi \\
\hline 2 & $\begin{array}{l}\text { Jam kerja saya sesuai dengan tingkat gaji yang saya } \\
\text { terima }\end{array}$ & 4,28 & Sangat Tinggi \\
\hline 3 & $\begin{array}{l}\text { Saya menganggap beban kerja pekerjaan saya } \\
\text { cukup adil }\end{array}$ & 3,81 & Tinggi \\
\hline 4 & $\begin{array}{l}\text { Saya merasa beban kerja yang saya hadapi sesuai } \\
\text { dengan kompensasi yang saya terima }\end{array}$ & 4,40 & Sangat Tinggi \\
\hline 5 & $\begin{array}{l}\text { Secara keseluruhan penghargaan (piala, sertifikat, } \\
\text { dll.) yang saya dapatkan sesuai dengan kompensasi }\end{array}$ & 3,91 & Tinggi \\
\hline
\end{tabular}




\begin{tabular}{|c|c|c|c|}
\hline No. & Item Variabel & Mean & Kategori \\
\hline & yang saya terima & & \\
\hline 6 & $\begin{array}{l}\text { Saya merasa imbalan yang saya dapatkan sesuai } \\
\text { dengan apa yang saya kerjakan }\end{array}$ & 4,31 & Sangat Tinggi \\
\hline 7 & $\begin{array}{l}\text { Saya merasa tanggung jawab pekerjaan saya sesuai } \\
\text { dengan kompensasi yang saya dapatkan }\end{array}$ & 4,12 & Tinggi \\
\hline 8 & $\begin{array}{l}\text { Kewajiban pekerjaan saya dalam perusahaan ini } \\
\text { sesuai dengan hak (kompensasi) yang saya terima }\end{array}$ & 4,05 & Tinggi \\
\hline & Rerata & 4,17 & Tinggi \\
\hline
\end{tabular}

Sumber : Data Primer Diolah, 2017

\section{Variabel Keadilan Prosedural Kompensasi}

Tabel 4.6

Penilaian Responden terhadap Keadilan Prosedural Kompensasi

\begin{tabular}{|c|l|c|l|}
\hline No. & \multicolumn{1}{|c|}{ Item Variabel } & Mean & \multicolumn{1}{|c|}{ Kategori } \\
\hline 1 & $\begin{array}{l}\text { Saya merasa keputusan terhadap kompensasi yang } \\
\text { dibuat oleh atasan dilakukan dengan cara yang tidak } \\
\text { memihak }\end{array}$ & 4,17 & Tinggi \\
\hline 2 & $\begin{array}{l}\text { Atasan selalu mendengarkan aspirasi saya terhadap } \\
\text { kompensasi }\end{array}$ & 3,68 & Tinggi \\
\hline 3 & $\begin{array}{l}\text { Atasan menjelaskan hasil keputusan tentang } \\
\text { kompensasi }\end{array}$ & 4,45 & Sangat Tinggi \\
\hline 4 & $\begin{array}{l}\text { Atasan menyediakan informasi tambahan tentang } \\
\text { kompensasi ketika saya meminta }\end{array}$ & 3,87 & Tinggi \\
\hline 5 & $\begin{array}{l}\text { Ketika ada masalah, atasan memberikan penjelasan } \\
\text { tentang kompensasi yang masuk akal bagi saya }\end{array}$ & 3,83 & Tinggi \\
\hline 6 & $\begin{array}{l}\text { Atasan selalu mengerti terhadap masalah } \\
\text { kompensasi sesuai dengan apa yang saya inginkan }\end{array}$ & 3,56 & Tinggi \\
\hline 7 & $\begin{array}{l}\text { Atasan menunjukkan kepedulian terhadap hak-hak } \\
\text { kompensasi) saya sebagai seorang karyawan }\end{array}$ & 4,32 & Sangat Tinggi \\
\hline \multicolumn{2}{|c|}{ Rerata } & 3,98 & Tinggi \\
\hline
\end{tabular}

Sumber : Data Primer Diolah, 2017

\section{Variabel Employee Engagement}

\section{Tabel 4.7}

Penilaian Responden terhadap Employee Engagement

\begin{tabular}{|c|l|c|l|}
\hline No. & \multicolumn{1}{|c|}{ Item Variabel } & Mean & \multicolumn{1}{|c|}{ Kategori } \\
\hline 1 & $\begin{array}{l}\text { Saya merasa memiliki tingkat kekuatan mental } \\
\text { yang tinggi dalam bekerja }\end{array}$ & 4,32 & Sangat Tinggi \\
\hline 2 & $\begin{array}{l}\text { Saya merasa memiliki tingkat resiliensi mental } \\
\text { yang tinggi dalam bekerja }\end{array}$ & 3,91 & Tinggi \\
\hline 3 & $\begin{array}{l}\text { Saya berusaha dengan sungguh-sungguh di dalam } \\
\text { pekerjaan }\end{array}$ & 4,15 & Tinggi \\
\hline 4 & Saya gigih dalam menghadapi kesulitan & 3,81 & Tinggi \\
\hline 5 & Saya memiliki perasaan yang penuh makna & 3,73 & Tinggi \\
\hline 6 & Saya antusias dalam bekerja & 4,17 & Tinggi \\
\hline 7 & Saya memiliki inspirasi dalam bekerja & 3,78 & Tinggi \\
\hline 8 & Saya memiliki kebanggaan dalam pekerjaan & 4,27 & Sangat Tinggi \\
\hline 9 & Pekerjaan saya cukup menantang. & 4,04 & Tinggi \\
\hline 10 & $\begin{array}{l}\text { Saya selalu berusaha berkonsentrasi dalam } \\
\text { pekerjaan }\end{array}$ & 3,87 & Tinggi \\
\hline 11 & $\begin{array}{l}\text { Saya memiliki minat yang mendalam dalam } \\
\text { pekerjaan }\end{array}$ & 3,84 & Tinggi \\
\hline 12 & Saya tenggelam dalam pekerjaan & 4,26 & Sangat Tinggi \\
\hline 13 & Saya merasa waktu terasa berlalu begitu cepat & 4,04 & Tinggi \\
\hline 14 & Saya merasa sulit melepaskan diri dari pekerjaan & 4,02 & Tinggi \\
\hline
\end{tabular}




\begin{tabular}{|c|c|l|l|}
\hline No. & Item Variabel & Mean & \multicolumn{1}{c|}{ Kategori } \\
\hline \multicolumn{2}{|c|}{ Rerata } & 4,02 & Tinggi \\
\hline
\end{tabular}

Sumber : Data Primer Diolah, 2017.

\section{Variabel Kinerja Karyawan}

\section{Tabel 4.8}

Penilaian Responden terhadap Kinerja Karyawan

\begin{tabular}{|c|l|l|l|}
\hline No. & Variabel & Mean & Kategori \\
\hline 1 & $\begin{array}{l}\text { Saya dapat menyelesaikan sejumlah pekerjaan } \\
\text { yang menjadi tanggung jawab Saya. }\end{array}$ & 4,34 & Sangat Tinggi \\
\hline 2 & $\begin{array}{l}\text { Saya dapat menyelesaikan sejumlah pekerjaan } \\
\text { dengan efektif dan efisien. }\end{array}$ & 4,23 & Sangat Tinggi \\
\hline 3 & $\begin{array}{l}\text { Saya dapat menyelesaikan pekerjaan dengan teliti } \\
\text { sesuai dengan yang diharapkan. }\end{array}$ & 4,19 & Tinggi \\
\hline 4 & $\begin{array}{l}\text { Saya dapat menyelesaikan pekerjaan dengan cepat } \\
\text { sesuai dengan yang diharapkan. }\end{array}$ & 3,81 & Tinggi \\
\hline 5 & $\begin{array}{l}\text { Saya memiliki pengetahuan yang cukup tentang } \\
\text { tugas-tugasnya sebagai bawahan. }\end{array}$ & 3,78 & Tinggi \\
\hline 6 & $\begin{array}{l}\text { Saya memiliki pengetahuan yang cukup tentang } \\
\text { kewajiban-kewajibannya sebagai bawahan. }\end{array}$ & 4,17 & Tinggi \\
\hline 7 & $\begin{array}{l}\text { Saya memiliki kemampuan bekerjasama dengan } \\
\text { orang lain. }\end{array}$ & 4,19 & Tinggi \\
\hline 8 & $\begin{array}{l}\text { Saya memiliki sikap yang konstruktif dalam } \\
\text { kelompok. }\end{array}$ & 4,02 & Tinggi \\
\hline 9 & $\begin{array}{l}\text { Saya memiliki sikap yang baik dalam menjalankan } \\
\text { pekerjaan. }\end{array}$ & 4,34 & Sangat Tinggi \\
\hline 10 & $\begin{array}{l}\text { Saya memiliki tanggung jawab yang besar dalam } \\
\text { menjalankan pekerjaan. }\end{array}$ & 4,23 & Sangat Tinggi \\
\hline 11 & $\begin{array}{l}\text { Saya memiliki inisiatif dalam menjalankan } \\
\text { tugas/pekerjaan. }\end{array}$ & 3,91 & Tinggi \\
\hline 12 & $\begin{array}{l}\text { Saya memiliki ide/gagasan dalam menjalankan } \\
\text { tugas/pekerjaan. }\end{array}$ & 3,72 & Tinggi \\
\hline 13 & $\begin{array}{l}\text { Saya memiliki kreatifitas untuk menyelesaikan } \\
\text { pekerjaan. }\end{array}$ & 3,98 & Tinggi \\
\hline 14 & $\begin{array}{l}\text { Saya memiliki kreatifitas untuk mencapai hasil } \\
\text { yang lebih baik. }\end{array}$ & 4,26 & Sangat Tinggi \\
\hline Rerata & 4,08 & Tinggi \\
\hline Sara & & \\
\hline
\end{tabular}

Sumber : Data Primer Diolah, 2017.

\section{Menilai Goodness of Fit (Uji Kesesuaian n Model)}

Tabel 4.9

\begin{tabular}{|c|c|c|c|}
\hline Goodness of Fit & Hasil Analisis & Cut off Value & Keterangan \\
\hline Chi-square & 1790,720 & $<321,417$ & Unfit \\
\hline Probability & 0,000 & $<0,05$ & Goodfit \\
\hline CMIN/DF & 2,094 & $>2$ & Marjinal \\
\hline RMSEA & 0,109 & $<0,80$ & Goodfit \\
\hline GFI & 0,552 & $>0,90$ & Unfit \\
\hline AGFI & 0,504 & $>0,90$ & Unfit \\
\hline TLI & 0,708 & $>0,90$ & Unfit \\
\hline CFI & 0,724 & $>0,95$ & Unfit \\
\hline
\end{tabular}


Sumber : Hasil Olah Data Structural Equation Modeling (SEM), 2018

\section{Hasil Goodness of Fit Inde}

Hasil Analisis Regresi Linier Model Jalur 1

Tabel 4.10

Hasil Regresi Linier Model SEM

\begin{tabular}{|l|c|c|c|}
\hline \multicolumn{1}{|c|}{ Variabel } & Koefisien Regresi & t-hitung & Probabilitas \\
\hline $\begin{array}{l}\text { Keadilan Distributif } \\
\text { Kompensasi }\left(\mathrm{X}_{1}\right)\end{array}$ & 0,602 & 4,983 & 0,000 \\
\hline $\begin{array}{l}\text { Keadilan Prosedural } \\
\text { Kompensasi }\left(\mathrm{X}_{2}\right)\end{array}$ & 0,379 & 4,044 & 0,000 \\
\hline $\mathrm{N}$ & $: 93$ \\
\hline \multicolumn{2}{|c|}{ Variabel Dependen (Z): Employee Engagement } \\
\hline
\end{tabular}

\section{Hasil Analisis Regresi Linier Model Jalur 2 \\ Tabel 4.11 \\ Hasil Regresi Linier Model SEM}

\begin{tabular}{|l|c|c|c|}
\hline \multicolumn{1}{|c|}{ Variabel } & \multicolumn{1}{|c|}{$\begin{array}{c}\text { Koefisien } \\
\text { Regresi }\end{array}$} & t-hitung & Probabilitas \\
\hline $\begin{array}{l}\text { Keadilan Distributif } \\
\text { Kompensasi }\left(\mathrm{X}_{1}\right)\end{array}$ & 0,312 & 2,183 & 0,029 \\
\hline $\begin{array}{l}\text { Keadilan Prosedural } \\
\text { Kompensasi }\left(\mathrm{X}_{2}\right)\end{array}$ & 0,379 & 4,044 & 0,000 \\
\hline $\begin{array}{l}\text { Employee } \\
\text { Engagement }(\mathrm{Z})\end{array}$ & 0,592 & 3,209 & 0,001 \\
\hline $\mathrm{N}$ & $: 93$ & & \\
\hline Variabel Dependen (Y) : Kinerja Karyawan & \\
\hline
\end{tabular}

Sumber: Data Primer Diolah, 2017

Berikut ini tabel ringkasan hipotesis:

Tabel 4.12

Ringkasan Hipotesis

\begin{tabular}{|c|c|c|}
\hline Hipotesis & Variabel & Keterangan \\
\hline $\mathrm{H}_{1}$ & $\mathrm{X}_{1}-\mathrm{Z}$ & Ha diterima \\
\hline $\mathrm{H}_{2}$ & $\mathrm{X}_{2}-\mathrm{Z}$ & Ha diterima \\
\hline $\mathrm{H}_{3}$ & $\mathrm{X}_{1}-\mathrm{Y}$ & Ha diterima \\
\hline $\mathrm{H}_{4}$ & $\mathrm{X}_{2}-\mathrm{Y}$ & Ha diterima \\
\hline $\mathrm{H}_{5}$ & $\mathrm{Z}-\mathrm{Y}$ & Ha diterima \\
\hline
\end{tabular}

Sumber : Data Primer Diolah, 2017

\section{KESIMPULAN}

a. Hasil analisis SEM menunjukkan bahwa Keadilan Distributif Kompensasi berpengaruh signifikan terhadap Employee Engagement Karyawan PT. Ameya Livingstyle Indonesia (nilai probabilitas $t_{\text {-hitung }}(0,000)<$ Level of Significant $\left.(0,05)\right)$. Hal ini dapat diartikan, jika Keadilan 
Distributif Kompensasi meningkat, maka Employee Engagement Karyawan PT. Ameya Livingstyle Indonesia mengalami peningkatan.

b. Hasil analisis SEM menunjukkan bahwa Keadilan Prosedural Kompensasi berpengaruh signifikan terhadap Employee Engagement Karyawan PT. Ameya Livingstyle Indonesia (nilai probabilitas $t_{\text {-hitung }}(0,000)<$ Level of Significant $\left.(0,05)\right)$. Hal ini dapat diartikan, jika Keadilan Prosedural Kompensasi meningkat, maka Employee Engagement Karyawan PT. Ameya Livingstyle Indonesia mengalami peningkatan.

c. Hasil analisis SEM menunjukkan bahwa Keadilan Distributif Kompensasi berpengaruh signifikan terhadap Kinerja Karyawan PT. Ameya Livingstyle Indonesia (nilai probabilitas t. hitung $(0,029)<$ Level of Significant $(0,05))$. Hal ini dapat diartikan, jika Keadilan Distributif Kompensasi meningkat, maka Kinerja Karyawan PT. Ameya Livingstyle Indonesia mengalami peningkatan.

d. Hasil analisis SEM menunjukkan bahwa Keadilan Prosedural Kompensasi berpengaruh signifikan terhadap Kinerja Karyawan Karyawan PT. Ameya Livingstyle Indonesia (nilai probabilitas $t_{\text {-hitung }}(0,000)<$ Level of Significant $\left.(0,05)\right)$. Hal ini dapat diartikan, jika Keadilan Prosedural Kompensasi meningkat, maka Kinerja Karyawan Karyawan PT. Ameya Livingstyle Indonesia mengalami peningkatan.

e. Hasil analisis SEM menunjukkan bahwa Employee Engagement mempunyai pengaruh secara simultan terhadap Kinerja Karyawan Karyawan PT. Ameya Livingstyle Indonesia (nilai probabilitas $t_{\text {-hitung }}(0,001)<$ Level of Significant $\left.(0,05)\right)$. Hal ini dapat diartikan, jika Employee Engagement meningkat, maka Kinerja Karyawan PT. Ameya Livingstyle Indonesia mengalami peningkatan.

\section{DAFTAR PUSTAKA}

Arikunto, Suharsimi. 2013. Prosedur Penelitian Suatu Praktek. Jakarta: Rineka Cipta.

Atmojo,S.T. dan Tjahjono,H.K. 2016. Pengaruh Keadilan Distributif dan Prosedural Kompensasi

Terhadap Kepuasan Kerja dan Kinerja Paramedis di Rumah Sakit. JBTI. Vol.7 No.1.

Yohanes,B. dan Wardani,P.R., 2005. Peran Keadilan Distributif, Keadilan Prosedural, dan Keadilan Interaksional Perusahaan terhadap Komitmen Karyawan pada Perusahaan (Studi pada Perusahaan X). Jurnal Psikologi Vol. 3 No.2.

Colquitt, J.A., Wesson. M. J., Porter, Christopher O.L.H., Conlon, Donald E., dan Yee Ng., K. 2013. Justice at the Millenium: A Meta-Analytic Review of 25 years of Organizational Justice Research. Journal of Applied Psychology. 86(3). pp: 425-445.

Cropanzano, R., Prehar, C. A., dan Chen, P.Y. 2007. Using Social Exchange Theory to Distinguish Procedural from Interactional Justice. Group and Organization Management. 27. 324-351.

Clayton, S. dan Opotow, S. 2003. Justice and Identity: Changing Perspectives on What is fair. Personality and Social Psychology Review, 7(4): 298-310.

Gilliland, S.W. 1994. Effects of Procedural and Distributive Justice on Reactions to a Selection System. Journal of Applied Psychology. 79(5). 691-701.

Greenberg, J., dan Baron, RA., 2003. Behavior in Organizations. Eightr Edition, Prentice Hall, New Delhi.

Handoko, T.H., 2008. Manajemen,. Edisi Kedua. Yogyakarta: BPFE.

Hasibuan, Malayu SP. 2003. Organisasi dan Motivasi, Dasar Peningkatan Produktivitas. Jakarta : Bumi Aksara.

Irawan, Luthfi. 2015. Pengaruh Keadilan Distributif dan Keadilan Prosedural Pada Komitmen Afektif dengan Kepuasan Kerja Sebagai Variabel Mediasi (Studi pada Karyawan PT. 
Tanjung Kreasi Parquet Industry Temanggung). Skripsi. Jurusan Manajemen. Fakultas Ekonomi. Universitas Negeri Semarang.

Kadaruddin, Abd., Rahman Kadir, Ria Mardiana Y., 2007. Pengaruh Keadilan Distributif, Keadilan Prosedural Dan Keadilan Interaksional Terhadap Kepuasan Kepuasan Pegawai Pajak di

Kota Makassar. Publikasi Penelitian. Manajemen dan Keuangan, Fakultas Ekonomi, Universitas Hasanuddin.

Lewis. R. Philipus. 2013. Keadilan Distributif, Keadilan Prosedural, Keadilan Interaksional Kompensasi dan Komitmen Karyawan. JRMB. Volume 8. No.1.

Luthans, Fred. 2006. Perilaku Organisasi. Yogyakarta: CV Ardi Ofsett.

Lind, E.A. \& Tyler, T.R. 1988. The Social Psychology of Procedural Justice. New York: Planum.

Mangkuprawira S., dan Vitalaya HA. 2007. Manajemen Mutu Sumber Daya Manusia. Bogor: Ghalia Indonesia.

Margaretha, Meily dan T. Elisabeth C.S., 2012. Keadilan Prosedural dan Keadilan Distributif sebagai Prediktor Employee Engagement. Jurnal Manajemen. Vol.12, No.1.

Masterson, S.S., Lewis, K., Goldman, B.M. and Taylor, M.S. 2000. Integrating Justice and Social Exchange: the Differing Effects of Fair Procedures and Treatment on Work Relationships. Academy of Management Journal, 43(4); 738-748.

Murtaza, G., Shad, I., Shahzad, K., Shah, M. K., dan Khan, N. A. 2011. Impact of Distributive and Procedural Justice on Employees'Commitment: A Case of Public Sector Organization of Pakistan. European Journal of Economics, Finance and Administrative Sciences. 29: 73-80

Prawirosentono, Suyadi. 2008. Kebijakan Kinerja Karyawan. Edisi Pertama. Yogyakarta: BPFE.

Ruslan, Rosady. 2004. Metode Penelitian Public Relations dan Komunikasi. Jakarta: PT. Raja Grafindo Persada.

Rahayu, Sri. 2005. SPSS Versi 12.00. Dalam Riset Pemasaran. Bandung: Alfabeta.

Robbins, P. Stephen, \& Coulter. 2008. Perilaku Organisasi Konsep, Kontroversi, Aplikasi. Alih Bahasa: Hadyana Pujaatmaka dan Benyamin Molan; Editor: Agus Widyantoro). Jakarta: Prenhallindo.

Simamora, Henry. 2006. Manajemen Sumber Daya Manusia. Edisi Tiga. Yogyakarta: STIE YKPN. Sugiyono. 2010. Metode Penelitian Bisnis. Bandung: CV. Alfabeta.

Sutrisna, I.W.W., dan Agoes, G.R., 2015. Pengaruh Keadilan Distributif, Prosedural, dan Interaksional terhadap Kepuasan Kerja dan Komitmen Organisasi Pada Paramedis di Rumah Sakit TK II Udayana Denpasar. Publikasi Penelitian. Fakultas Ekonomi dan Bisnis Universitas Udayana (Unud) Bali.

Tjahjono, H.K., 2005. Praktik-praktik Manajemen SDM Strategik; Pengujian Universalistik dan Kontijensi dalam Menjelaskan Kinerja Organisasional. Jurnal Bisnis dan Ekonomi Kinerja. 9(2):123-134.

Tjahjono, H.K., 2008. Studi Literatur Pengaruh Keadilan Distributif dan Keadilan Prosedural pada Konsekuensinya dengan Teknik Meta Analisis. Jurnal Psikologi. Volume 35(1). 21-40, Universitas Gadjah Mada Yogyakarta.

Tjahjono, H.K.,2014. The Fairness Of Organization's Performance Appraisal, Social Capital and the Impact Toward Affective Commitment. International Journal of Administrative Science \& Organization. 21(3): 173-179.

Tyler, T.R. \& Blader, S.L. 2003. The Group Engagement model: Procedural Justice, Social Identity, and Cooperative Behavior. Personality and Social Psychology Review. 7(4):349-361. 